\title{
The Israeli national population program of genetic carrier screening for reproductive purposes
}

\author{
Joël Zlotogora, MD, $\mathrm{PhD}^{1-4}$, Itamar Grotto, MD, $\mathrm{PhD}^{2,3,5}$, Ehud Kaliner, $\mathrm{MD}, \mathrm{MPH}^{2,3}$ and \\ Ronni Gamzu, MD, PhD 3
}

Purpose: The Israeli population genetic screening program for reproductive purposes, launched in January 2013, includes all known, nationally frequent severe diseases (carrier frequency 1:60 and/or disease frequency 1 in 15,000 live births). The carrier screening program is free of charge and offers testing for cystic fibrosis, fragile X syndrome, and spinal muscular atrophy for nearly the entire population, according to disease frequency among the different groups within the population. We report the results of the first year of the program.

Methods: Data on the tests performed over a 12-month period were collected from laboratories nationwide.

Results: More than 62,000 individuals were examined. The carrier frequency was within the expected range for most of the diseases. The

The initiation in 1971 of a screening program to prevent TaySachs disease among Ashkenazi Jews in the United States ${ }^{1}$ led to the establishment of a similar program in Israel under the aegis of the Ministry of Health. A national carrier screening program for the prevention of $\beta$-thalassemia was subsequently implemented in Israel for the Arab population and some Jewish communities in which the disease is relatively frequent. ${ }^{2}$ It quickly became apparent that the Tay-Sachs prevention program was not applicable to the ultraorthodox Ashkenazi Jewish community because of their belief-based objection to pregnancy termination as a means of prevention. Therefore, a special program ("Dor Yeshorim") was designed and implemented in that community with the purpose of preventing the marriage of two heterozygotes with mutations in the same gene. ${ }^{3}$

The ability to perform a molecular diagnosis of many genetic diseases that are frequent among different ethnic groups within the Israeli population introduced many disorders as candidates for screening. These screening tests had been offered privately and later had been partially covered by nonmandatory comprehensive health insurance held by three-fourths of the population. In 2004, the Association of Israeli Medical Geneticists recommended including in the national carrier screening program for reproductive purposes all severe genetic diseases with a carrier frequency of 1:60 and/or with a disease incidence higher than 1 in 15,000 live births. Such expansion, however, was only gradually sponsored by the Ministry of Health because of budgetary limitations. The first step was taken in few exceptions included lower carrier rates for cystic fibrosis among Muslim Arabs (1:236) and Druze (1:1,021) and Niemann-Pick type A among Muslim Arabs in a delineated region of Israel (1:229).

Conclusion: The national population genetic carrier screening is aimed toward providing couples with knowledge of the existing options for the prevention of serious genetic conditions when it is relevant for them. It is still too early to determine whether this aim has been achieved.

Genet Med advance online publication 16 April 2015

Key Words: Arabs; Druze; Jews; Israel; population genetic screening

2002, and it targeted severe genetic diseases with an incidence higher than $1: 1,000 .{ }^{4}$ Next, screening for cystic fibrosis (CF) and familial dysautonomia in at-risk populations began at the end of 2008. Launched in January 2013, the national program now includes all the severe genetic diseases with a carrier frequency of 1:60 and/or with a disease incidence higher than 1 in 15,000 live births, as recommended by the Association of Israeli Medical Geneticists. ${ }^{5}$ These are the results of the first year of its implementation.

\section{The population}

\section{MATERIALS AND METHODS}

At the end of 2013, there were 8,134,500 inhabitants in Israel, comprising 6,104,500 Jews (75.1\%), 1,420,300 Muslim Arabs (17.5\%), 160,900 Christian Arabs (2.0\%), and 134,000 Druze (1.6\%). ${ }^{6}$ There were 171,444 live births in 2013, among which 126,999 were Jews (74.1\%), 34,927 Muslim Arabs (20.4\%), 2,602 Christian Arabs (1.5\%), and 2,350 Druze (1.4\%). ${ }^{6}$

\section{The screening program}

The program is targeted to at-risk populations and includes carrier screening for CF, fragile X syndrome (FXS), and spinal muscular atrophy (SMA) for most of the population. It also includes tests for all severe diseases with a carrier frequency of 1:60 or higher that are performed among Jews according to the community of origin, among Arabs and Druze according to the religion and the locality of origin, or according to the tribe

${ }^{1}$ Department of Community Genetics; ${ }^{2}$ Public Health Services; ${ }^{3}$ Ministry of Health, Jerusalem, Israel; ${ }^{4}$ Hadassah Medical School, Hebrew University, Jerusalem, Israel;

${ }^{5}$ Faculty of Health Sciences, Ben Gurion University of the Negev, Beer Sheva, Israel. Correspondence: Joël Zlotogora (zlotogora@gmail.com)

Submitted 24 December 2014; accepted 17 March 2015; advance online publication 16 April 2015. doi:10.1038/gim.2015.55 
among the Bedouins of the Negev. The definition of "origin" applied to those for whom at least one ancestor had that origin.

The screening is performed either before or during a pregnancy. It is targeted to couples, and the tests are free of charge when both partners are from the at-risk population. The basis of the program is sequential screening; most often the woman is tested first and if she is found to be a carrier, her partner is also tested. An exception is the "Dor Yeshorim" program, in which both potential spouses are tested.

The tests are performed either in medical genetic units or in community clinics under the supervision of a physicianmedical geneticist. Written recommendations and explanations are given before data on the couple's origin are taken by either genetic counselors or a staff member who received appropriate tutoring under the responsibility of the medical geneticist in charge. Individuals from a family with a known medical problem are referred to genetic counseling before the tests are performed. If testing reveals that the person is a carrier, the results are reported by a genetic counselor. At-risk couples receive genetic counseling and may choose any of the reproductive options, again free of charge. Couples may also undergo the tests through the "Dor Yeshorim" premarital option that does not include FXS screening because a positive result could preclude the marriage of a carrier woman.

The screening for thalassemia is performed first according to blood count indexes (those results were not available for this report). The mutations tested for all the diseases that were screened in more than one locality/tribe participating in the screening program are listed in Supplementary Table S1 online.

\section{Data collection}

The 14 different participating laboratories (including "Dor Yeshorim") reported to the Ministry of Health the tests performed during the 12 months between 1 February 2013 to 31
January 2014. Because of differences in recording policies, the data were not always complete, mostly with regard to ethnicity or religion.

\section{RESULTS}

\section{Test results}

The results of the tests performed in more than 62,000 individuals are given in Table 1 and the supplementary material (Supplementary Tables S2-S7 online). The tests were classified according to the population screened. The number of tests for which the rates were calculated was smaller than the actual number of individuals examined because complete data on ethnic origins were not always available.

Cystic fibrosis. The screening for $\mathrm{CF}$ is done in most of the population, excluding some of the Jewish community such as Jews from Ethiopia and most of the Bedouin of the Negev. Among the 59,644 individuals for whom data were available, the carrier rate was 1:45. Among 34,399 individuals for whom origin was reported, 674 of 27,347 Jews were carriers (1:41). Among the 5,428 Muslim Arabs 23 were carriers (1:236), among the 603 Christian Arabs 7 were carriers (1:86), and among the 1,021 Druze 1 was a carrier.

Spinal muscular atrophy. Screening for SMA is done in the entire population. Among the in 62,444 individuals for whom data were available, the carrier rate was 1:57. Among the 47,158 individuals for whom origin was reported, 650 of 36,933 Jews were carriers (1:57). Among the 7,767 Muslim Arabs 106 were carriers (1:73), among the 1,091 Christian Arabs 38 were carriers (1:29), and among the 1,367 Druze 29 were carriers (1:47).

Fragile $X$. Among the 44,592 women for whom data were available, the FXS carrier rate was 1:149. Among those the

Table 1 Population carrier screening: results of the tests performed in more than one locality/tribe

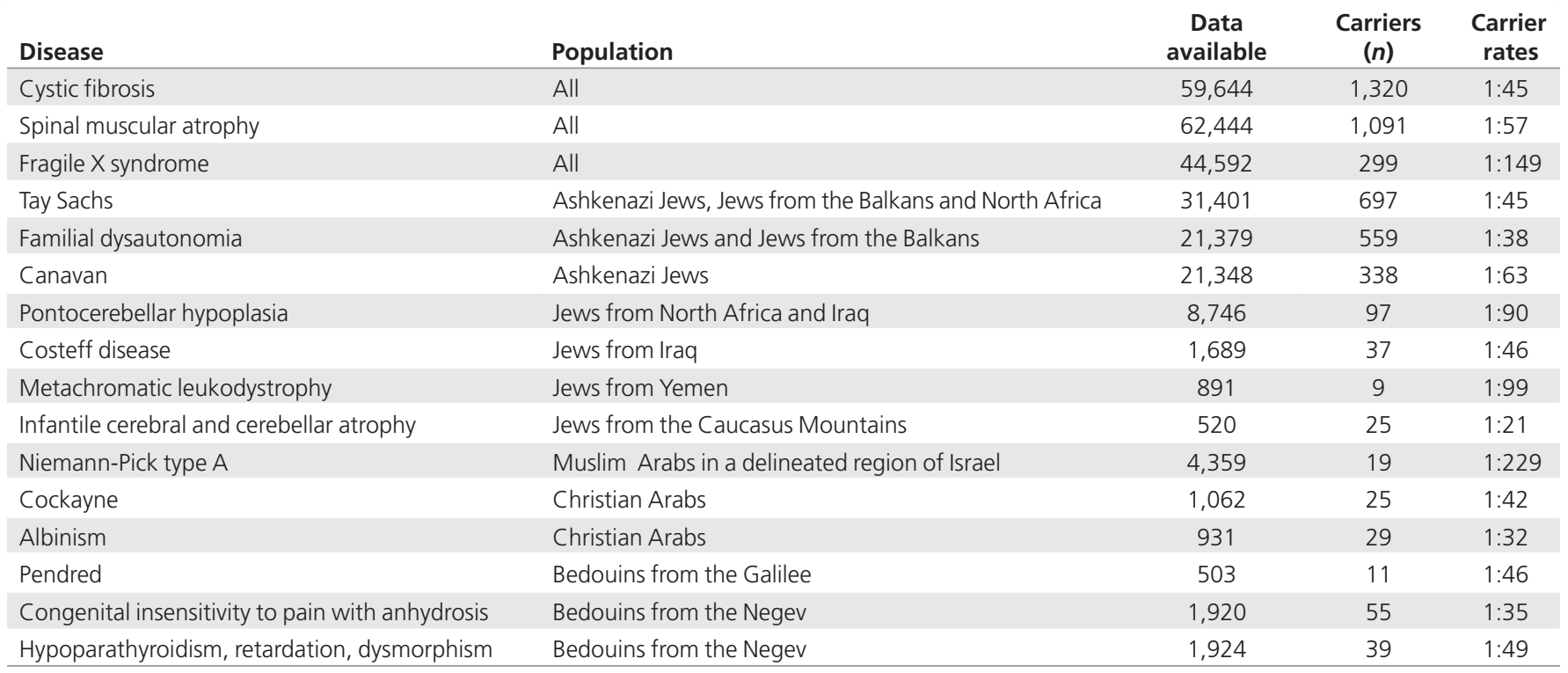


origin was reported for 26,019, and of 19,418 Jews, 160 were carriers (1:121). Among the 4,750 Muslin Arabs 18 were carriers (1:264). Among the 604 Christian Arabs 8 were carriers (1:76), and among the 1,517 Druze 2 were carriers (1:759).

\section{DISCUSSION}

The relative abundance of severe genetic diseases among Ashkenazi Jews posed a challenge for the public health system in Israel. ${ }^{7}$ Genetic carrier screening for reproductive objectives that was first introduced by the Ministry of Health in Israel for Tay Sachs disease resulted in the near disappearance of the disease among Jews. Later, genetic screening for additional diseases was recommended by the Association of Israeli Medical Geneticists, and it was offered privately first for CF, then for FXS, and subsequently for other diseases. The overwhelming success of the Tay Sachs program was probably behind the high acceptance of these recommendations among the Jewish population. ${ }^{5}$ However, many of the at-risk individuals-especially the non-Jewish ones-did not undergo the tests that were not in the "basket of services" provided by national health insurance. ${ }^{8}$ Those diseases are one cause of the high rate of infant mortality among Arabs, particularly among Bedouins, ${ }^{9}$ highlighting the need for the introduction of all genetic tests to detect carriers for severe genetic diseases that have a frequency of 1:60 or higher. The results presented here demonstrate for the first time that a large proportion of the population, including its different subgroups, participated in the screening. At least 10,225 of the 62,444 individuals screened for SMA for whom data were available were non-Jews, representing $16.4 \%$ of the individuals screened, which is close to their share within the population.

The Israeli genetic screening program is unique not only in offering screening for CF, FXS, and SMA free of charge to nearly the entire population but also in being tailored according to ethnicity and religion. Distinguishing between different ethnicities and religions may be objectionable in other countries, but it is well accepted in Israel for the purposes of equality of rights and privileges. In addition, the country of origin among Jews and non-Jews has solid health relevance. Another unique perspective of this tailored screening approach is the option of the "Dor Yeshorim" program, directed to the ultrareligious Jewish community. ${ }^{3}$ The aim of this premarital screening program for couples is to avoid the marriage of individuals at risk for the same autosomal recessive disease. While among the ultrareligious Jews the tests are done before marriage, in the other communities, we do not have exact knowledge of the period in which the tests are done-either before or during pregnancy.

Differential screening of Israeli Jews is expected to be replaced by a single test that includes all the mutations ubiquitous in that population since there has been a steady increase in the mixing of Jews of different ethnic origins. Such an approach has been proposed by several groups and is beginning to be implemented. ${ }^{10}$ One problem is that in a sequential screening program such as the one currently implemented in Israel, a universal test will increase the cases in which one individual is found to be a carrier whereas the other partner is from a community in which the disease is rare. This will invariably increase the couple's level of anxiety and lead to additional tests (e.g., sequencing) that are not justified. Couple screening would, therefore, be a better approach because the results are given as the "risk of the couple" instead of the individual. ${ }^{11}$

Among Jews, the carrier frequency observed after the first year of the program was within the range of the expectations for most of the screened diseases (Table 1). Much data on the carrier frequency were already available for many of the diseases frequent among the Ashkenazi Jews. ${ }^{10,12-14}$ For diseases that are relatively frequent in the other non-Ashkenazi communities, however, this report is the first to outline carrier frequency based on relatively large numbers of screened individuals. In the few instances where the carrier frequency was lower than expected (Table 1), it was still more than the $1 \%$ frequency recommended for screening by the American College of Medical Genetics and Genomics. ${ }^{15}$

A different situation was observed for the non-Jewish subgroups because there were no previous data on carrier frequency based on relatively large numbers of screened individuals. The first-year results of the expanded program indicate that the carrier rates of SMA were high in the three non-Jewish subgroups. While the carrier rates for CF were relatively low among Christian Arabs (1:86), they were low among Muslim Arabs (1:236) and very low among Druze (1:1,021). Among the Druze, carrier rates for FXS were also relatively low (1:759). The Druze population has been relatively isolated, and this can probably explain these differences in the rates of CF and FXS. ${ }^{16}$ Among the other diseases examined in the non-Jewish population, the carrier rates were in the expected range, although in most cases the small number of screened individuals precluded drawing any conclusions. The only disease in which the carrier rate was significantly less than expected (1:229) was NiemannPick type A among Muslim Arabs in a delineated region of Israel $^{17}$ (Table 1).

The program described herein is planned to be dynamic and altered according to the results and the new data on additional diseases that meet the inclusion criteria. We intend to continue to follow the program and to collect supplementary data in particular about the percentages of tests done before or during pregnancy and about the decisions of the couples discovered through the program. The purpose of the national population genetic carrier screening is to provide couples the possibility of preventing the birth of an affected child. Obligatory reporting of children born with the screened diseases has been implemented since the national program was introduced. Follow-up of the affected children will allow the determination of whether the couples knew about the existing options for prevention of serious genetic conditions when it was relevant for them. 


\section{SUPPLEMENTARY MATERIAL}

Supplementary material is linked to the online version of the paper at http://www.nature.com/gim

\section{ACKNOWLEDGMENTS}

This article represents the opinions of the authors and not necessarily those of the Israeli Ministry of Health.

\section{DISCLOSURE}

The authors declare no conflict of interest.

\section{REFERENCES}

1. Kaback MM. Screening and prevention in Tay-Sachs disease: origins, update, and impact. Adv Genet 2001;44:253-265.

2. Koren A, Zalman L, Palmor $\mathrm{H}$, et al. [The prevention programs for beta thalassemia in the Jezreel and Eiron valleys: results of fifteen years experience]. Harefuah 2002;141:938-43, 1210.

3. Ekstein J, Katzenstein H. The Dor Yeshorim story: community-based carrier screening for Tay-Sachs disease. Adv Genet 2001;44:297-310.

4. Zlotogora J, Carmi R, Lev B, Shalev SA. A targeted population carrier screening program for severe and frequent genetic diseases in Israel. Eur I Hum Genet 2009;17:591-597.

5. Zlotogora J. Genetics and genomic medicine in Israel. Mol Genet Genomic Med 2014;2:85-94.

6. Statistical Abstracts of Israel, Jerusalem, Israel, 2014. http://www.cbs.gov.il/ reader/shnatonenew_site.htm

7. Zlotogora J, Leventhal A. Screening for genetic disorders among Jews: how should the Tay-Sachs screening program be continued? Isr Med Assoc J 2000;2:665-667.
8. Sukenik-Halevy R, Leil-Zoabi UA, Peled-Perez L, Zlotogora J, Allon-Shalev S Compliance for genetic screening in the Arab population in Israel. Isr Med Assoc J 2012;14:538-542.

9. Zlotogora J, Leventhal A, Amitai Y. The impact of congenital malformations and Mendelian diseases on infant mortality in Israel. Isr Med Assoc J 2003;5:416-418.

10. Lazarin GA, Haque IS, Nazareth $S$, et al. An empirical estimate of carrier frequencies for $400+$ causal Mendelian variants: results from an ethnically diverse clinical sample of 23,453 individuals. Genet Med 2013;15:178-186.

11. Wald NJ, George LM, Wald NM, Mackenzie I. Couple screening for cystic fibrosis. Lancet 1993;342:1307-1308.

12. Ben-Shachar S, Orr-Urtreger A, Bardugo E, Shomrat R, Yaron Y. Large-scale population screening for spinal muscular atrophy: clinical implications. Genet Med 2011;13:110-114.

13. Berkenstadt M, Ries-Levavi L, Cuckle H, Peleg L, Barkai G. Preconceptional and prenatal screening for fragile $X$ syndrome: experience with 40,000 tests. Prenat Diagn 2007;27:991-994.

14. Hoffman JD, Park JJ, Schreiber-Agus N, et al. The Ashkenazi Jewish carrier screening panel: evolution, status quo, and disparities. Prenat Diagn 2014;34:1161-1167.

15. Monaghan KG, Feldman GL, Palomaki GE, Spector EB; Ashkenazi Jewish Reproductive Screening Working Group; Molecular Subcommittee of the ACMG Laboratory Quality Assurance Committee. Technical standards and guidelines for reproductive screening in the Ashkenazi Jewish population. Genet Med 2008;10:57-72.

16. Zidan J, Ben-Avraham D, Carmi S, Maray T, Friedman E, Atzmon G. Genotyping of geographically diverse Druze trios reveals substructure and a recent bottleneck. Eur J Hum Genet; e-pub ahead of print 5 November 2014.

17. Gluck I, Zeigler M, Bargal R, Schiff E, Bach G. Niemann Pick Disease type A in Israeli Arabs: 677delT, a common novel single mutation. Mutations in brief no. 161. Online. Hum Mutat 1998:12:136. 